\title{
REDUCTION AND IMMOBILIZATION OF RADIONUCLIDES AND TOXIC METAL IONS USING COMBINED ZERO VALENT IRON AND ANAEROBIC BACTERIA
}

Lenly J. Weathers and Lynn E. Katz Department of Civil and Environmental Engineering

University of Maine

Orono, Maine

Year One Technical Progress Report

Submitted to the Department of Energy

October, 1997 


\section{Research Hypothesis}

Previous research findings indicate that both zero valent iron and sulfate reducing bacteria can yield significant decreases in $\mathrm{Cr}(\mathrm{VI})$ or $\mathrm{U}(\mathrm{VI})$ concentrations due to abiotic and microbial reduction, respectively. The major hypothesis associated with this research project is that a combined abiotic-biological system can synergistically combine both processes to maximize metal ion reduction in an engineered permeable reactive barrier.

Recent research also provides a range of hypotheses regarding the reaction mechanisms for these processes and identifies numerous potential parameters which may affect the rates of reduction for abiotic and microbial metal ion reduction. Therefore, the second major hypothesis associated with this proposal is that design of either in-situ or ex-situ metal ion reduction processes based on biotic, abiotic or a combined abiotic/biotic reduction scheme requires a more thorough understanding of the rates of the reaction and quantification of the parameters which impact the rates of reduction.

\section{Objectives}

The overall goal of this project is to design a combined abiotic/microbial, reactive, permeable, in-situ barrier with sufficient reductive potential to prevent downgradient migration of toxic metal ions. The field-scale application of this technology would utilize anaerobic digester sludge, $\mathrm{Fe}(\mathrm{O})$ particles for supporting anaerobic biofilms, and suitable aquifer material for construction of the barrier. Successful completion of this goal requires testing of the two hypotheses listed above by evaluating:

1. the rates of abiotic metal ion reduction under a range of environmental conditions including

a) initial $\mathrm{Cr}(\mathrm{VI})$ or $\mathrm{U}(\mathrm{VI})$ concentration

b) $\mathrm{Fe}(\mathrm{O})$ surface area added to the system

c) source of $\mathrm{Fe}(\mathrm{O})$ including varying degree of $\mathrm{Fe}(0)$ purity

d) background soil properties including mineral composition and ability to evaluate the role of soil components in reducing $\mathrm{Cr}(\mathrm{VI})$ or $\mathrm{U}(\mathrm{VI})$ in the absence of $\mathrm{Fe}(\mathrm{O})$

e) the presence of competing surface adsorbates

f) the types and role of passive films that form on $\mathrm{Fe}(0)$ surfaces

2. the rates of microbial metal ion reduction in microbial and combined abiotic/microbial reduction systems under a range of environmental conditions including

a) initial $\mathrm{Cr}(\mathrm{VI})$ or $\mathrm{U}(\mathrm{VI})$ concentration

b) $\mathrm{Fe}(\mathrm{O})$ surface area to control $\mathrm{H}_{2}$ production required for $\mathrm{SRB}$ growth in combined microbial/abiotic reduction systems

c) background soil properties including mineral composition

d) sulfate concentration

e) biomass concentration

The experimental approach based on these objectives will lead to an increased understanding of the performance of reactive, iron barriers for the removal of $\mathrm{Cr}(\mathrm{VI}), \mathrm{U}(\mathrm{VI})$ and other toxic metal ions under sulfate-reducing conditions. 


\section{Research to Date}

The major goals for Year 1 were to establish the sulfate reducing mixed culture, to obtain sources of iron metal, and to conduct background experiments which will establish baseline rates for abiotic chromium reduction rates. Research completed to date is described below.

Task 1: Characterization of $\mathrm{Fe}(\mathrm{O})$ and Aquifer Material

A number of $\mathrm{Fe}(\mathrm{O})$ sources have been selected for use in subsequent tasks. Three chemical grade iron powders, one steel wool and one batch of commercial grade iron filings have been obtained:

1. Alfa Aeasar 40 mesh spherical powder

2. Alfa Aeasar 200 mesh powder

3. Alfa Aeasar palladium-coated 40 mesh iron powder

4. Rhodes American steel wool

5. Scrap steel filings (approximately 8 to 50 mesh) from Peerless Supply, Inc.

Task 2: Fe(O) Batch Reactor Studies

The purpose of this task is to determine the rate of reduction of $\mathrm{Cr}(\mathrm{VI})$ or $\mathrm{U}(\mathrm{VI})$ under various experimental conditions. As a first step in this task, methods for measuring selected analytes were developed. The compounds and their respective analytical methods include:

1. Cr(VI): measured by diphenylcarbazide method (Standard Method 312B)

2. Total chromium: measured by atomic absorption

3. Fe(II): measured by phenanthroline method (Standard Method 315B)

4. Total iron: determined by sample reduction, then phenanthroline method

5. H,: measured by headspace analysis, GC-TCD

6. Sulfate: measured by IC

7. Sulfide: measured by iodometric method (Standard Method 427D)

The rates of reduction of $\mathrm{Cr}(\mathrm{VI})$ under various reaction schemes was examined by periodically sampling replicate 12-ml plastic centrifuge tubes, 120-mL HDPE serum bottles or 500-mL HDPE plastic bottles containing iron metal or other potential reducing agents; buffered, deoxygenated, Nanopure water; and chromium. To initiate an experiment, all of the reagents except chromium were added and the systems were pre-equilibrate for several hours. At the start of an experiment (time $=0), \mathrm{Cr}(\mathrm{VI})$ was injected and the tubes or bottles were sealed and placed on a shaker. Experiments were conducted to measure the reduction of $\mathrm{Cr}^{6+}$ by $1-4$ grams of 40 mesh iron powder, 200 mesh iron powder, or steel wool. Initial $\mathrm{Cr}^{6+}$ concentrations varied from 20 to $160 \mathrm{ppm}$. Experiments were conducted using unbuffered water or bicarbonate-buffered solutions, and at various $\mathrm{pH}$ values. Based on the results of the experiments conducted to date, the following findings were obtained from the data:

1. In the absence of reducing agents, there was no noticeable reduction in $\mathrm{Cr}^{6+}$. These experiments were conducted using deoxygenated, unbuffered Nanopure water in centrifuge tubes or HDPE bottles, $\left[\mathrm{Cr}^{6+}\right]_{0}=20-160 \mathrm{ppm}$.

2. In the presence of 40 mesh iron powder, the decrease of $\mathrm{Cr}^{6+}$ was similar to, but more rapid than, that reported in Powell et al.' For example, with $\left[\mathrm{Cr}^{6+}\right]_{0}=160 \mathrm{ppm}$ and $4 \mathrm{~g}$ powder (40 mesh) in a 12-n-L centrifuge tube containing $10 \mathrm{~mL}$ deoxygenated, unbuffered Nanopure water, we observed 50\% reduction in about 7 hours vs. 50 hours for Powell et al.

'Powell, R.M., R.W. Puls. S.K. Hightower, and D.A. Sabatini (1995) Coupled Iron Corrosion and Chromate Reduction: Mechanisms for Subsurface Remediation, Environ. Sci. and Technol., 29, 1913-1922. 
3. There appeared to be no effect of sulfate in similar systems. For example, $4.2 \mathrm{~g}$ powder (40 mesh) in a $12-\mathrm{mL}$ centrifuge tube containing $10 \mathrm{~mL}$ of a $5.9 \mathrm{mM}$ sulfate solution, $\left[\mathrm{Cr}^{6+}\right]_{0}=$ 160 ppm: no noticeable difference between these reactors and control reactors containing 10 $\mathrm{mL}$ deoxygenated, unbuffered Nanopure water.

4. Hydrogen gas appeared to have no effect on chromium reduction. For example, $120-\mathrm{mL}$ HDPE serum bottles containing $100 \mathrm{~mL}$ deoxygenated, Nanopure water and $20 \mathrm{~mL} \mathrm{H}_{2}$ gas, $\left[\mathrm{Cr}^{6+}\right]_{0}=20$ ppm: no noticeable decrease in $\mathrm{Cr}^{6+}$ concentration.

5. Chromium was rapidly reduced in the presence of sulfide and the rate of reduction increased with decreasing $\mathrm{pH}$. These results are consistent with Pettine et al. ${ }^{\text {ii }}$ For example, with a borate-buffered $(9 \mathrm{mM})$ solution containing $162 \mathrm{mM}$ sulfide, $0.5 \mathrm{M} \mathrm{NaCl}$, and [Cr"], = 396 $\mu \mathrm{M}$ : pseudo-first order rate coefficients of 0.024 and $0.011 \mathrm{~min}^{-1}$ were obtained at $\mathrm{pH}$ values of 6.94 and 7.68, respectively.

Based on these results, we are developing a rate model. This model will incorporate the amount of solid phase present, either $\mathrm{Fe}(\mathrm{O})$ or $\mathrm{FeS}$; and aqueous phase concentrations of sulfide, $\mathrm{Fe}^{2+}$, and H'.

We have submitted a proposal for beamtime to perform X-ray absorption spectroscopy at the Stanford Synchrotron Radiation Laboratory on samples from our systems. In addition, we will also utilize thermogravimetric analysis and X-ray photoelectron spectroscopy to examine solid phases and surfaces formed in our systems.

Task 3: Experiments with Aquifer Materials and $\mathrm{Fe}(\mathrm{O})$

The goal of the experimental work in this task is to evaluate the effect of aquifer materials on $\mathrm{Cr}(\mathrm{VI})$ or U(VI) reduction. Samples will be prepared, sampled and analyzed using the same procedures as those outlined in Task 2 except that aquifer material will be added to the sample at three different mass levels with and without the presence of $\mathrm{Fe}(\mathrm{O})$. However, the range of variables in Task 3 will be significantly reduced based on the results of Task 2 . Only those parameters which have been shown to have a significant effect on reduction rates will be varied in Task 2. These experiments will be conducted in Years 2 and 3.

Task 4 Determination of the Rates of Reduction and Extent of Metal Ion Toxicity to Anaerobic Bacteria in Batch Reactors

Task 4 has two goals: 1) to examine the impact of metal ion concentration on microbial metal ion reduction and on the metabolism of $\mathrm{H}_{2}$ or acetate; and 2) to provide insight into the ecological relationship between acetogens, methanogens and sulfate-reducing bacteria with regard to microbial metal ion reduction and the metabolism of hydrogen and acetate. Hydrogen is of interest because it is produced during anaerobic iron corrosion. Acetate will be studied because homoacetogenic bacteria may produce acetate from hydrogen.

Task 4a. Culture Development: A hydrogen-oxidizing, sulfate-reducing mixed culture has been developed as an inoculum source for biological experiments. The stock reactor is a stirred, 20-L glass vessel containing $15 \mathrm{~L}$ of cell suspension. The culture was seeded using digested sewage sludge from the Ellsworth, Maine, wastewater treatment plant, and is maintained at $30^{\circ} \mathrm{C}$ on a mineral salts medium. The chemostat is fed lactate and is operated with a 15-day hydraulic

"Pettine, M.. F.J. Millero and R. Passino (1994) Reduction of chromium (VI) with hydrogen sulfide in NaCl media. Marine Chem., 46, 335-344. 
retention time. The biomass concentration is about $200 \mathrm{mg} \mathrm{VSS/L}$. Biomass, sulfate and sulfide concentrations; and $\mathrm{pH}$ of the reactor are routinely measured. Lactate is measured by HPLC. Methane is measured by GC-FID.

Task 4b. Batch Experiments: Preliminary experiments have been conducted to confirm the hydrogenotrophic, sulfate-reducing nature of the mixed culture. Experiments were performed in 160-mL glass serum bottles containing $100 \mathrm{~mL}$ anaerobic cell suspension. Reactors received $1200 \mu \mathrm{mol} \mathrm{H}$ gas; $10 \mathrm{~g}$ iron filings (40 mesh) or steel wool; or no exogenous electron donor. The initial sulfate concentration was $13 \mathrm{mM}$. Cell-free controls were prepared using sulfidereduced media. After 10 days, hydrogen was nondetectable in treatments receiving $1200 \mu \mathrm{mol}$ $\mathrm{H}_{2}$ gas, while the hydrogen concentration was $1100 \mu \mathrm{mol} \mathrm{H}_{2}$ gas per bottle in cell-free controls. Sulfate reduction was coincident with the decrease of hydrogen. These results are consistent with the hypothesis that the mixed culture contains hydrogen-oxidizing, sulfate-reducing bacteria. Furthermore, after six days the concentration of hydrogen in bottles was: $150 \mu \mathrm{mol} \mathrm{H}_{2}$ per bottle for the cell-free/iron filing controls; $1450 \mu \mathrm{mol} \mathrm{H}_{2}$ per bottle for the cell-free/steel wool controls; nondetectable for the live/iron filing treatments; and $31 \mu \mathrm{mol} \mathrm{H}_{2}$ per bottle for the live cell/steel wool treatments. Sulfate reduction was also coincident with the decrease in hydrogen. These results are consistent with the hypothesis that the oxidation of $\mathrm{Fe}(\mathrm{O})$ is coupled with the reduction of water-derived protons, and the hydrogen is consumed by sulfate-reducing bacteria, as originally proposed by von Wolzogen Kühr and van der Vlugt ${ }^{\text {iii }}$.

Task 4c. Metal Ion-Acclimated Enrichment Cultures: These studies will be conducted in Years 2 and 3 .

Task 5: Evaluate the Effect of Biomass/Fe(O) Ratio on Metal Ion Reduction in a Batch Reactor System that Contains Suspended Growth Anaerobic Bacteria and $\mathrm{Fe}(\mathrm{O})$

Studies will be conducted in Years 2 and 3 using four biomass concentrations: 0, 25\%, 50\%, and $100 \%$ of the biomass concentration of the stock culture reactor. Diluted biomass will be prepared using the mineral salts media for the stock culture reactor, or using autoclaved cell suspension taken from the stock reactor. Experiments will be conducted as described in Task $4 \mathrm{~b}$ using one of the iron types examined using bicarbonate as a buffer in Task 2. The mass of iron for these experiments will be determined based on the results of Task 2 .

Task 6: Evaluate Abiotic and Combined Abiotic/Microbial Cr(VI) Reduction in a Fixed-Film, Continuously Stirred Tank Reactor (CSTR) to Evaluate the Role of Biofilms on Metal Ion Reduction

The goal of Task 6 is to compare the metal ion removal kinetics in a reactor in which an SRI3 biofilm is attached to a reactive, iron surface with the kinetics in a biofilm-free reactor of similar construction. These studies will be conducted in Years 2 and 3.

\footnotetext{
"' von Wolzogen Kühr. C.A.H. and L.S. van der Vlugt, (1934), The graphitization of cast iron as an electrochemical process in anaerobic soils, Water, 18, 147-165.
} 